\title{
Nerve growth factor increases MMP9 activity in annulus fibrosus cells by upregulating lipocalin 2 expression
}

\author{
Ting-Hsien Kao $\cdot$ Yi-Jen Peng $\cdot$ Donald M. Salter • \\ Herng-Sheng Lee
}

Received: 26 March 2014/Revised: 12 November 2014/Accepted: 13 November 2014/Published online: 21 November 2014

(C) The Author(s) 2014. This article is published with open access at Springerlink.com

\begin{abstract}
Purpose Nerve growth factor (NGF) expression and activity is important in chronic lower back pain but may also act as a pro-catabolic factor in the pathogenesis of intervertebral disc (IVD) degeneration. Lipocalin 2 (Lcn2) expression in IVD was upregulated by NGF stimulation in our previous study. The current study was undertaken to identify potential mechanisms of the latter effect including potential interactions between Lcn2 and matrix metalloproteinase 9 (MMP9).

Methods Rat annulus fibrosus (AF) cells were stimulated by NGF and subjected to microarray analysis, subsequent real-time PCR, western immunoblotting, and immunofluorescence. Cells were treated with NGF in the absence or presence of the NGF inhibitor Ro 08-2750. Zymography and functional MMP9 assays were used to determine
\end{abstract}

Electronic supplementary material The online version of this article (doi:10.1007/s00586-014-3675-2) contains supplementary material, which is available to authorized users.

T.-H. Kao · H.-S. Lee

Graduate Institute of Medical Science, National Defense

Medical Center, Taipei, Taiwan, Republic of China

T.-H. Kao

Functional Neurosurgery Division, Neurological Institute,

Taichung Veterans General Hospital, Taichung, Taiwan,

Republic of China

T.-H. Kao

Department of Acupressure Technology, Jen-Teh Junior College of Medicine, Nursing and Management, Miaoli County, Taiwan, Republic of China

Y.-J. Peng - H.-S. Lee

Department of Pathology, Tri-Service General Hospital and

National Defense Medical Center, Taipei, Taiwan,

Republic of China
MMP9 activity, whilst the dimethyl-methylene blue assay was used to quantify the release of glycosaminoglycans (GAGs) reflecting catabolic effects following NGF treatment. Immunoprecipitation with immunoblotting was used to identify interactions between MMP9 and Lcn2.

Results Increased expression of Lcn2 gene and protein following NGF stimulation was confirmed by microarray analysis, real-time PCR, western blot and immunofluorescence. Zymography showed that NGF enhanced $125-\mathrm{kDa}$ gelatinase activity, identified as a Lcn2/MMP9 complex by immunoprecipitation and immunoblotting. Functional assays showed increased MMP9 activity and GAG release in the presence of NGF. The effects of NGF were neutralized by the presence of Ro 08-2750.

Conclusions NGF upregulates Lcn2 expression and increases MMP9 activity in AF cells; processes which are likely to potentiate degeneration of AF tissue in vivo. AntiNGF treatment may have benefit for management of pain

\section{M. Salter}

Osteoarticular Research Group, Centre for Genomics and Experimental Medicine, Institute of Genetics and Molecular Medicine, University of Edinburgh, Edinburgh, UK

H.-S. Lee $(\square)$

Department of Pathology and Laboratory Medicine, Kaohsiung Veterans General Hospital, No. 386, Dazhong 1st Rd., Zuoying District, Kaohsiung 81362, Taiwan, Republic of China e-mail: herngsheng131419@gmail.com; joshua_kth@yahoo.com.tw 
relief and slowing down progression of AF tissue degeneration.

Keywords Low back pain - Annulus fibrosus - Nerve growth factor $\cdot$ Lipocalin $2 \cdot$ MMP9

\section{Introduction}

Chronic low back pain (LBP) is a relatively common condition with a number of possible etiologies including intervertebral disc (IVD) degeneration, spondylolisthesis, diskitis or spondylitis [1, 2]. The pathogenesis of the chronic LBP associated with IVD degeneration is complex but changes in IVD innervation appear to be important [3]. In the normal IVD, nerve fibers, derived from branches of sympathetic trunk and sinuvertebral nerves, are present only in the outer annulus fibrosus (AF) and vertebral endplate [4]. During IVD degeneration, however, nerve fiber ingrowth into the nucleus pulposus (NP) is seen and is believed to possibly contribute to chronic LBP [5]. Consequent therapies targeting neuronal transmission pathways are increasingly being thought to be useful for alleviating pain $[6,7]$. It is becoming clear, however, that neurotrophins such as NGF and brain-derived neurotrophic factor (BDNF) have a wide range of activities other than neurotransmission that include roles in tissue development, repair, modulation of inflammatory responses and bone and cartilage metabolism [8-11].

In addition to inducing nerve ingrowth, NGF appears to have other effects that are likely to contribute IVD degeneration. Matrix degradation as a result of over production of matrix metalloproteinases (MMPs) is a major component of the pathological processes that lead to IVD degeneration [12] and NGF has been shown to increase MMP expression in a number of tissues and cell systems [13]. Furthermore, NGF has been shown to induce neoangiogenesis in a range of normal and pathological conditions [14]. As such NGF appears to be a prime target for intervention in the course of IVD degeneration with the potential to both ameliorate pain and decrease or reverse the rate of disease progression. NGF influences expression of several catabolic genes in animal and human IVD cells including ch3ll, lipocalin 2 (lcn2), mmp3 and mmpl3 according to our previous microarray-based study [15]. Since Lcn2 protein has been reported as forming a complex with MMP9 to protect it from degradation and thereby enhancing its catabolic function in osteoarthritic cartilage [16], the current study was undertaken to test the hypothesis that NGF regulates expression of lipocalin 2 in AF cells resulting in an increase in MMP9 activity which would potentially contribute to IVD degeneration.

\section{Materials and methods}

Experimental animals and ethics statement

Two-month-old skeletally mature male Sprague-Dawley rats (weight 380-420 g) were obtained from the National Applied Research Laboratories and National Laboratory Animal Center (Taiwan). All experimental procedures were approved by the Institutional Animal Care and Use Committee of Taichung Veterans General Hospital (La-101983).

\section{Reagents}

Rat beta-nerve growth factor (NGF) was purchased from R\&D System Inc. (Minneapolis, MN, USA). NGF stock solution at a concentration of $100 \mu \mathrm{g} / \mathrm{mL}$ was prepared in sterile phosphate-buffered saline (PBS) containing $0.1 \%$ bovine serum albumin (BSA). Ro 08-2750 was purchased from TOCRIS bioscience (Bristol, UK). A stock solution at a concentration of $10 \mu \mathrm{M}$ was prepared in dimethyl sulfoxide (DMSO). Rat IL-1 $\beta$ was purchased from R\&D Systems Inc. IL-1 $\beta$ stock solution at a concentration of $100 \mu \mathrm{g} / \mathrm{mL}$ was prepared in PBS containing $0.1 \%$ BSA.

\section{Isolation and expansion of rat disc cells}

AF tissue of rat-tail intervertebral discs (Coccygeal Co4thCo6th level) was dissected carefully with minimal NP or other tissue contamination by an experienced spinal surgeon. The dissected tissue was then cut into small pieces, incubated with antimicrobial solution for $4 \mathrm{~h}$ and then washed with sterile PBS before digestion with $3 \mathrm{mg} / \mathrm{mL}$ collagenase type H (Sigma-Aldrich Inc., St. Louis, MO, USA) at $37{ }^{\circ} \mathrm{C}$ for $6 \mathrm{~h}$. The resultant cell suspension was centrifuged at 1,000 rpm for $10 \mathrm{~min}$ following which the supernatant was discarded and the pellet re-suspended in PBS. After a further wash, cells were re-suspended and seeded in $10 \mathrm{~mL}$ of Dulbecco's modified Eagle's medium/Nutrient Mixture F-12 HAM medium (Gibco, Carlsbad, CA, USA) containing $10 \%$ FBS (Gibco), $100 \mathrm{IU} / \mathrm{mL}$ penicillin (Gibco) and $100 \mathrm{mg} / \mathrm{mL}$ streptomycin (Gibco). The cells were then cultured in a humidified $5 \% \mathrm{CO}_{2}$ incubator at $37{ }^{\circ} \mathrm{C}$ until confluent. Cells between passages 3 and 5 were used.

\section{Experimental protocol}

Cells were seeded at a density of $1 \times 10^{6}$ cells/dish in 60-mm Petri dishes. Dishes of rat disc cells were placed in $3 \%$ FBS media, then incubated with either $100 \mathrm{ng} / \mathrm{mL} /$ day of NGF and/or $10 \mathrm{nM} /$ day of Ro $08-2750$ at $37{ }^{\circ} \mathrm{C}$ for 5 days. Media were collected for immunoprecipitation and Fluorescence Resonance Energy Transfer (FRET)-based assay. 
Microarray assay

The detailed microarray methods and results were provided in our previous study [15]. Briefly, gene expression analysis of rat-tail disc cells with or without NGF stimulation for 5 days was undertaken using the Rat Whole Genome OneArray $^{\mathrm{TM}}$ (Phalanx Biotech Group, Hsinchu, Taiwan), signals being scanned by an Axon 4000 scanner (Molecular Devices, Sunnyvale, CA, USA). The fluorescent intensity of each spot was analyzed by genepix 4.1 software (Molecular Devices) with the signal intensity of each spot being corrected by subtracting the background signal. The fold change of gene expression was calculated by dividing the normalized signal intensities of genes in NGF treated cells by those of untreated cells. Genes with fold changes $>2$ or $<-2$ were analyzed by Kyoto Encyclopedia of Gene and Genomes (KEGG) pathways on the Gene Ontology Tree Machine web site, a respected web-based and treebased data mining environment for gene sets. We used the gene Set Test function implemented in the limma $R$ package (Gordon Smyth) to test significant KEGG pathways. The Web Gestalt tool was used to test significant GO terms. The microarray data comply with MIAME guidelines, and the raw data have been deposited in a MIAMEcompliant database. The GEO microarray data number is GSE49560.

RNA extraction and real-time polymerase chain reaction

Total RNA from cell cultures was extracted using TRIzol ${ }^{\circledR}$ RNA Isolation Reagents (Invitrogen, NY, USA). For firststrand complementary DNA synthesis, $2 \mu \mathrm{g}$ of total RNA was used in a single-round reverse transcription reaction by High Capacity cDNA Reverse Transcription Kit (Applied Biosystems, Foster City, CA, USA). Complement DNAs were amplified under the following condition: $95{ }^{\circ} \mathrm{C}$ for $10 \mathrm{~min}, 40$ cycles of $95{ }^{\circ} \mathrm{C}$ for $15 \mathrm{~s}$ and $60{ }^{\circ} \mathrm{C}$ for $60 \mathrm{~s}$, using the Power SYBR ${ }^{\circledR}$ green PCR master mix (Applied Biosystems) and a StepOne ${ }^{\mathrm{TM}}$ Real-Time PCR System (Applied Biosystems). Amplification of glyceraldehyde-3phosphate dehydrogenase (Gapdh) simultaneously served as an internal control and allowed normalization of the various mRNA levels against the total mRNA content in the samples which was used to calculate changes in gene expression by $2^{-\Delta \Delta \mathrm{Ct}}$ formula. The specific primers used in this study are shown in Table 1.

\section{Protein extraction and western blotting}

Following stimulation, cells were immediately washed with ice-cold PBS containing $100 \mu \mathrm{M} \mathrm{Na} \mathrm{VO}_{4}$ (Sigma)
Table 1 Oligonucleotides primers for rat real-time PCR analysis

\begin{tabular}{lll}
\hline Gene & Accession no. & Sequence \\
\hline Gapdh & NM_017008.4 & 5'-CCCATCACCATCTTCCAGGAG-3' $^{\prime}$ \\
& & $5^{\prime}$-GTTGTCATGGATGACCTTGGC-3' \\
Lcn2 & NM_130741.1 & $5^{\prime}$-TCCATCCTCGTCAGGGGCCA-3' \\
& & $5^{\prime}$-AGTGTCGGCCACTTGCACATCG-3' \\
Mmp9 & NM_031055.1 & $5^{\prime}$-TGGCCTTTAGTGTCTCGCTGT-3' \\
& & $5^{\prime}$-CACACAGCTGGCAGAGGATT-3'
\end{tabular}

Annealing temperature: $60^{\circ} \mathrm{C}, 40$ cycles

and lysed in situ with ice-cold lysis buffer at $4{ }^{\circ} \mathrm{C}$ for 15 min. Lysis buffer contained $1 \%$ Igepal (Sigma), $100 \mu \mathrm{M} \mathrm{Na} \mathrm{VO}_{4}$, and protease inhibitor cocktail tablet (Roche Diagnostics, Mannheim, Germany). Whole cell lysates were collected after centrifugation at 13,000 rpm for $15 \mathrm{~min}$. Protein concentrations were determined by the Lowry method. Equal amounts of protein were loaded onto $10 \%$ SDS-polyacrylamide gel and subsequently transferred to polyvinylidene fluoride (PVDF) membranes (Millipore). Membranes were blocked overnight at $4{ }^{\circ} \mathrm{C}$ with $2 \%$ BSA in TBST. After washing three times with TBST, blots were incubated overnight with primary antiLcn2 antibody (1:1,000) (Abcam Ltd., Cambridge, UK) diluted in $2 \%$ BSA. After washing six times with TBST, blots were then incubated with the HRP-labeled secondary antibody for $1 \mathrm{~h}$ at room temperature. Membranes were rewashed extensively and antibody binding was detected using an enhanced chemiluminescence (ECL) plus Western blotting detection system (Amersham Biosciences, Buckinghamshire, UK) according to the manufacturer's instructions. The membranes were scanned and analyzed by densitometry (Fujifilm, LAS 300, Tokyo, Japan).

Immunofluorescence

After incubation with NGF for 5 days, cells were washed twice with ice-cold PBS and then fixed using $2 \mathrm{~mL}$ of a 1:1 methanol/acetone mixture for $5 \mathrm{~min}$ at $-20{ }^{\circ} \mathrm{C}$. For immunofluorescence, cells were washed twice with PBS before incubation with $1 \% \mathrm{BSA}$ for $30 \mathrm{~min}$ at room temperature. The solution was removed and cells were incubated sequentially with primary antibody [either antiLcn2 (1:100) or anti-MMP9 (1:100) (Abcam Ltd., Cambridge, UK)] for $60 \mathrm{~min}$, Alexa fluoro dye-conjugated secondary antibody (1:200) (Invitrogen, USA) for $45 \mathrm{~min}$. Following each incubation, cells were washed three times with Tris-buffered saline/Tween (TBST) (2.5 mM Tris/ $\mathrm{HCl}$, pH 7.6, $137 \mathrm{mM} \mathrm{NaCl}, 0.1 \%$ Tween 20), counterstained with DAPI (1:10,000) (Invitrogen) and visualized under fluorescence microscopy. 


\section{Zymography}

The culture medium was collected and mixed with sample buffer containing sodium dodecyl sulfate (SDS), glycerol and bromophenol blue. Equal amounts of each sample were separated on an SDS-polyacrylamide gel (8\%) containing $1 \mathrm{mg} / \mathrm{mL}$ gelatin. After SDS-polyacrylamide gel electrophoresis, the gels were washed twice with $2.5 \%$ Triton X-100 for 30 min to remove SDS, then twice with distilled water and were finally equilibrated with incubation buffer (100 mM Tris/ $\mathrm{HCl}, 30 \mathrm{mM} \mathrm{CaCl} 2,0.01 \% \mathrm{NaN}_{3}$ ). The gel was then incubated in incubation buffer for $20 \mathrm{~h}$ at $37{ }^{\circ} \mathrm{C}$ before staining with Coomassie Blue solution $(10 \mathrm{~mL}$ of acetic acid, $40 \mathrm{~mL}$ of distilled water, $50 \mathrm{~mL}$ of methanol, $0.25 \%$ Coomassie Blue G250) for 40 min. Destaining was performed in methanol/acetic acid/distilled water.

\section{Quantitation of glycosaminoglycans}

Total glycosaminoglycan (GAG) release was measured in media collected at day 5 using 1,9-dimethylmethylene blue (DMMB) assay. DMMB solution was prepared by dissolving $16 \mathrm{mg}$ DMMB (Sigma-Aldrich), $3.04 \mathrm{~g}$ glycine and $2.37 \mathrm{~g} \mathrm{NaCl}$ in deionized water (final volume $1 \mathrm{~L}, \mathrm{pH}$ 3.0). Standards were chondroitin sulfate sodium salt from shark cartilage (Sigma-Aldrich) soluble in PBS buffer, prepared ranging from 0 to $150 \mu \mathrm{g} / \mathrm{mL}$. $25 \mu \mathrm{L}$ of sample was added to a well of a 96-well plate followed immediately by addition of $125 \mu \mathrm{L}$ DMMB solution. Absorbance was measured at $525 \mathrm{~nm}$ by use of EnSpire multimode plate reader (PerkinElmer Inc., MA, USA).

\section{Immunoprecipitation and FRET assay}

Cultured media in the conditions of control, NGF, Ro 08-2750 and NGF + Ro 08-2750 were collected. For each condition, $3 \mathrm{~mL}$ of medium was concentrated to $0.5 \mathrm{~mL}$ with Spin-X UF centrifugal concentrators at 1,500 rpm for $1 \mathrm{~h}$ at $4{ }^{\circ} \mathrm{C}$ (Corning, MA, USA). Protein concentrations were determined by the Lowry method. Equal amounts of $500 \mu \mathrm{g}$ protein were incubated with anti-MMP9 antibody ( $1 \mathrm{mg} / \mathrm{mL}, 1 \mu \mathrm{L}$ ) overnight and immunoprecipitated with a Protein G Immunoprecipitation Kit (Sigma). Pull-down products were loaded onto $10 \%$ SDS-polyacrylamide gel and subsequently transferred to PVDF membranes (Millipore). Membranes were blocked overnight at $4{ }^{\circ} \mathrm{C}$ with $2 \%$ BSA in TBST. After washing three times with TBST, blots were incubated overnight with primary anti-Lcn 2 or anti-MMP9 antibody $(1: 1,000)$ (Abcam) diluted in $2 \%$ BSA. After washing six times with TBST, blots were then incubated with the HRP-labeled secondary antibody for $1 \mathrm{~h}$ at room temperature. Membranes were rewashed extensively and antibody binding was detected using an ECL plus Western blotting detection system (Amersham Biosciences) according to the manufacturer's instructions. The membranes were scanned and analyzed by densitometry (Fujifilm, LAS 300).

FRET assays were carried out according to the manufacturer's instructions. Briefly, MMP9 antibody (Abcam, Bristol, UK) was coupled to the resin. Cultured media were incubated with MMP9 antibody-coupled resin. Non-bound proteins were removed by washing and bound proteins were eluted with a low $\mathrm{pH}$ buffer. The eluted supernatant was incubated with AMPA (4-aminophenylmercuric acetate) for $2 \mathrm{~h}$ at $37{ }^{\circ} \mathrm{C}$ and then added to a MMP9 substrate solution using MMP9 assay kit (AnaSpec Inc., CA, USA). The fluorescence intensity was measured immediately using Synergy H4 (BioTek, VT, USA) with a filter set of excitation/emission $=485 \pm$ $20 \mathrm{~nm} / 528 \pm 20 \mathrm{~nm}$.

Statistical analysis

All values were expressed as mean \pm standard deviation (SD). Statistical evaluation of the quantification data of mRNA and protein expression levels was performed by Student's $t$ tests. The results were considered significant at a $P$ value $<0.05$.

\section{Results}

Effect of NGF on annulus fibrosus cell gene expression

Using purified RNA samples from the AF cells, we found that 97 of the 24,358 transcripts $(<0.4 \%)$ covered by Rat OneArray showed $>$ twofold change after NGF stimulation [15]. The top 30 upregulated genes by a $\log 2$ ratio of more than 1.5 are shown as supplementary data. NGF had no effect on cell viability over the time course of the experiment as assessed by an MTT assay (data not shown).

NGF increases Lcn2 gene and protein expression in rat AF cells

Among the genes identified as being upregulated in the microarray study, Lcn2 was selected for further investigation in view of previous published work that indicates potential roles for this molecule in protecting MMP9 activity on cartilage matrix breakdown [16]. Real-time PCR confirmed increased expression of Lcn2 following NGF stimulation (Fig. 1a). Western blotting demonstrated increased expression of Lcn2 protein in the NGF-stimulated cells (Fig. 1b). 
Fig. 1 Effect of NGF on Lcn2 gene and protein expression in AF cells. a Real-time PCR. $L c n 2$ expression is significantly increased $(18.00 \pm 1.92$-fold $)$ following NGF stimulation. b Western immunoblotting analysis shows a significant increase in Lcn2 protein $(4.3 \pm 1.5$-fold $)$ following NGF stimulation. $(n=5$, $* * * P<0.001)$
A

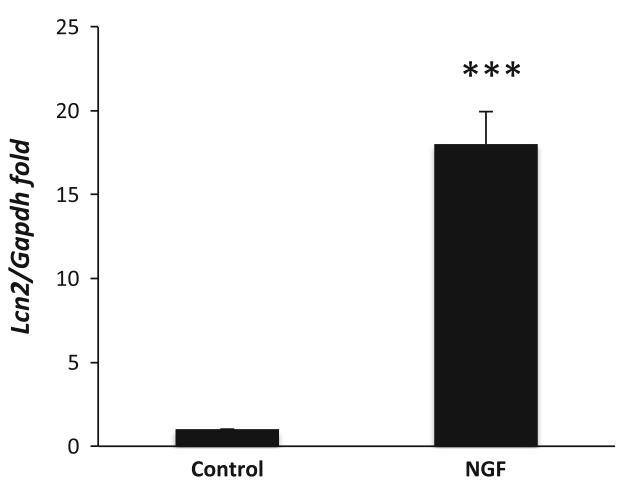

B
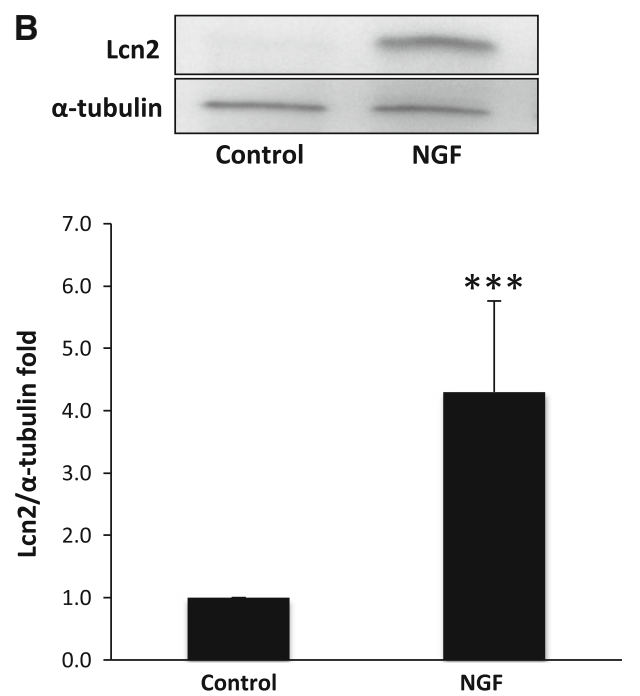

A specific NGF receptor inhibitor prevents NGF-

induced effects on Lcn2 gene and protein expression

To confirm that the changes in Lcn2 gene and protein expression were mediated through NGF receptor signaling, experiments were undertaken in the presence of Ro 08-2750, a non-peptide inhibitor of NGF that selectively binds to p75NTR at the concentration used in the current study. Rat AF cells were co-incubated with NGF (100 ng/ $\mathrm{mL} /$ day) with and without Ro 08-2750 (10 nM/day) for 5 days and $L c n 2$ and $M m p 9$ gene expression was analyzed by real-time PCR. The NGF-induced upregulation of $L c n 2$ was significantly inhibited by Ro 08-2750 (Fig. 2a). NGF alone had no significant effects on $\mathrm{Mmp} 9$ gene expression (Fig. 2b) consistent with results from the microarray analysis (not shown). Similarly, co-incubation of AF cells with NGF and Ro 08-2750 did not influence Mmp9 gene expression.

Effects of Ro 08-2750 on NGF-induced changes in Lcn2 protein expression were studied by western immunoblotting and immunofluorescence. Following NGF stimulation at a concentration of $100 \mathrm{ng} / \mathrm{mL} /$ day for 5 days, Lcn 2 protein expression is increased in AF cells but inhibited in the presence of Ro 08-2750 (Fig. 2c, d). MMP9 protein expression was increased following treatment of AF cells with NGF. Similar to the results seen on Len2 expression, no change in levels of MMP9 was observed when cells were treated with NGF in the presence of Ro 08-2750.

NGF treatment of AF cells enhances 125-kDa gelatinase activity

Lcn2 has been shown to form a complex with MMP9 to stabilize and protect MMP9 activity [16] and hence has the potential to enhance catabolic activity through this mechanism. To establish whether this was potentially the case in our model system, we undertook a series of studies using gelatin zymography (Fig. 3). In basal cultures, gelatin zymography showed that culture media from AF cultures were rich in 62-, 72-, 82-, 92-, and 125-kDa MMP activity. MMP activity at 92- and 82- $\mathrm{kDa}$ and $72-$ and $62-\mathrm{kDa}$ has previously been determined to represent latent and active forms of MMP9 and MMP2, respectively, whereas $125-\mathrm{kDa}$ activity has been demonstrated to be due to an Lcn2-MMP9 complex [16]. When NGF is added to the cultures, the $125-\mathrm{kDa}$ activity was increased significantly and inhibited by addition of the NGF inhibitor Ro 082750 (Fig. 3).

\section{Effects of NGF on GAG release in AF cell cultures}

When AF cells are cultured in monolayer, GAG is deposited in the pericellular matrix [17]. To establish whether NGF had pro-catabolic effects on GAG release, AF cells were cultured in the presence of NGF and GAG in the medium assessed. NGF at a concentration of $100 \mathrm{ng} / \mathrm{mL}$ significantly increased the amount of GAG within the media (Fig. 4) over a 5-day incubation although the effect is lower than seen with $10 \mathrm{ng} / \mathrm{mL}$ IL1 $\beta$ following $24-\mathrm{h}$ incubation. The pro-catabolic effect of NGF was inhibited by the presence of the specific NGF inhibitor Ro 08-2750. Ro 08-2750 had no effect on basal levels of GAG release.

Identification of Lcn2-MMP9 complex and MMP9 activity in culture medium

To confirm that the $125-\mathrm{kDa}$ gelatinase is an Lcn2-MMP9 complex, the collected media were subjected to immunoprecipitation with an anti-MMP9 antibody. Pull-down products were then immunoblotted with anti-MMP9 and 


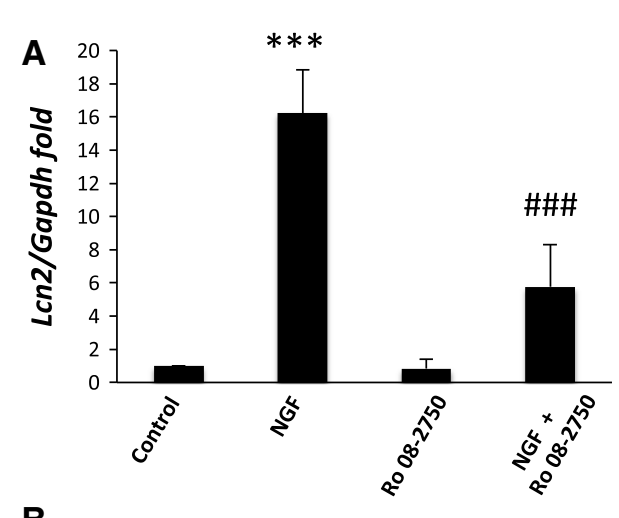

\section{C}
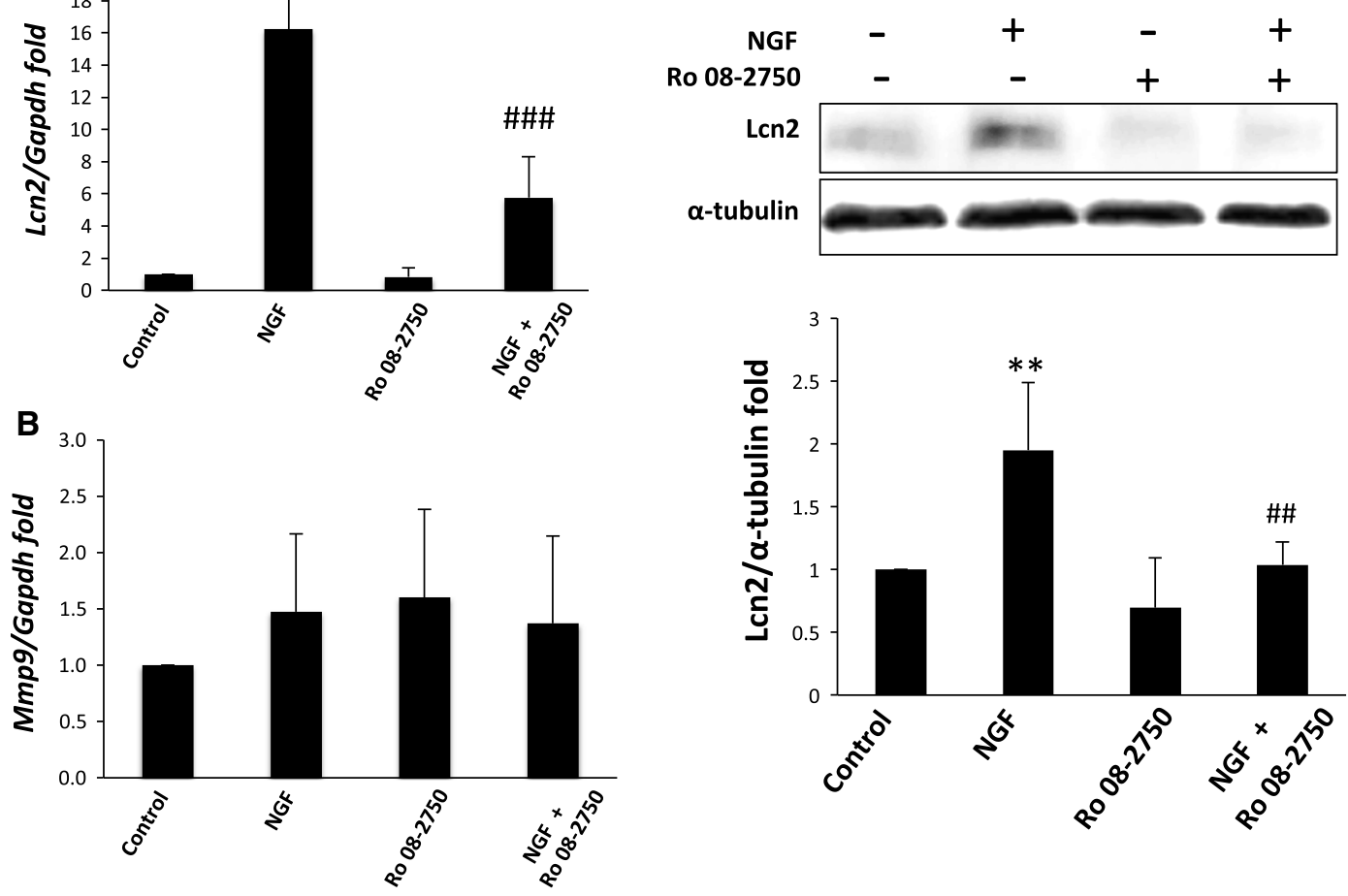

D

Len2

MMP9

(a)

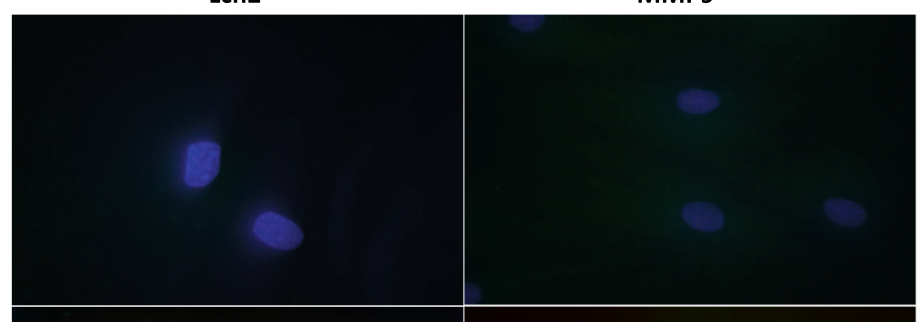

(b)

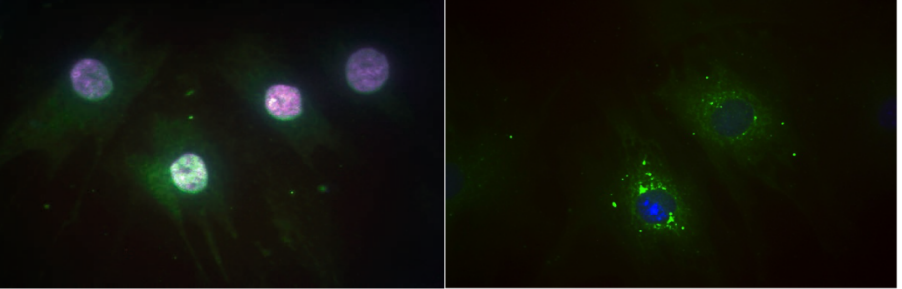

(c)

Ro 08-2750

(d)

NGF +

Ro 08-2750 
४Fig. 2 Ro 08-2750 decreases NGF-induced upregulation of Lcn2 expression in AF cells. a Upregulation (16.23 \pm 2.62 -fold) of Lcn2 expression by $100 \mathrm{ng} / \mathrm{mL}$ NGF was significantly decreased in the presence of $10 \mathrm{nM}$ Ro $08-2750 \quad(5.77 \pm 2.53$-fold $) . \quad n=6$. *** $P<0.001$ compared with control, ${ }^{\# \# \# ~} P<0.001$ compared with NGF. b NGF had no significantly upregulated effect on Mmp 9 gene expression ( $n=10$, NGF vs control, $P=0.095)$. c Upregulated Lcn2 by NGF was inhibited by Ro $08-2750(n=5$, NGF vs control, $* * P<0.01$; NGF vs NGF + Ro 08-2750, ${ }^{\# \#} P<0.01$ ). d Immunofluorescence showed increased expression of Lcn2 and MMP9 protein following stimulation by NGF only in the absence of Ro 08-2750. $a$ No stimulation. $b$ Cells incubated with NGF. $c$ Cells incubated with Ro 08-2750. $d$ Cells incubated with NGF and Ro 08-2750. $(n=3$, original magnification $\times 1000$ )
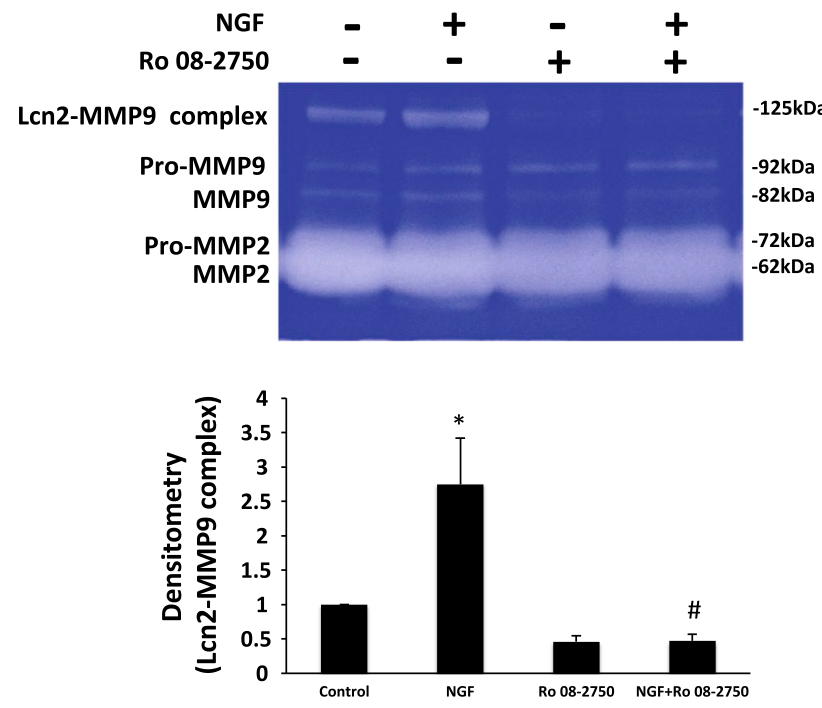

Fig. 3 Basal and NGF induction of Lcn2-MMP9 125-kDa gelatinase activity is inhibited by $10 \mathrm{nM}$ Ro 08-2750. Lcn2-MMP9 complex activity was upregulated by $100 \mathrm{nM}$ NGF stimulation (NGF vs control, $2.75 \pm 0.67$-fold, $* P=0.046)$ and inhibited by treatment with Ro 08-2750 (NGF vs NGF + Ro 08-2750, ${ }^{\#} P=0.023$ ). Upper panel was a representative gel and lower panel was the semiquantitative data $(n=3)$

anti-Lcn2 antibodies, respectively (Fig. 5a). Both MMP9 and Lcn2 release was increased following NGF stimulation and inhibited in the presence of Ro 08-2750. MMP9 activity in the medium was assayed by FRET functional analysis which demonstrated significantly increased activity of MMP9 following NGF stimulation which was inhibited by the presence of Ro 08-2750 (Fig. 5b).

\section{Discussion}

In this study, we have observed that NGF, which is likely to play a role in nerve ingrowth into the degenerated IVD $[5,18]$, may also act as a catabolic factor promoting disc degeneration [15]. The observation that NGF induced

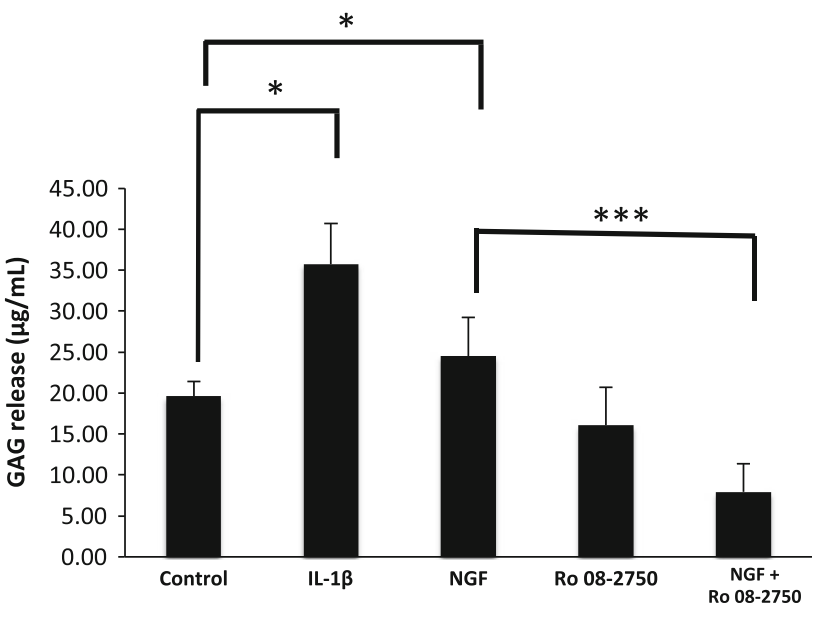

Fig. 4 Ro 08-2750 prevents NGF-induced GAG release in AF cell cultures. GAG release was significantly increased by NGF stimulation that was inhibited by treatment Ro $08-2750$. IL-1 $\beta$ (10 ng/mL for $24 \mathrm{~h})$ served as positive control for GAG release. $(n=6, * P<0.05$, $* * * P<0.001)$

overexpression of lipocalin 2 to enhance MMP9 activity in AF cells is previously unreported.

Lcn2 is a multifunctional $25-\mathrm{kDa}$ protein that has roles in innate immunity and tumourigenesis. Also known as neutrophil gelatinase-associated lipocalin (NGAL), Lcn2 is now recognized as an adipokine as it is predominantly produced by white adipose tissue [19]. Lcn2 has recently been identified in growth plate chondrocytes [20] where expression is modulated by IL-1 $\beta$, leptin, adiponectin, lipopolysaccharides, and dexamethasone. The function of Lcn2 in cartilage and IVD tissue is currently unknown. However, activity in these tissues is most probably related to one or more of the multifaceted functions of this molecule identified in other tissues. These include promoting angiogenesis [21] and enhancing matrix degradation through interactions with MMP9 [16]. With respect to the latter activity, dimerization of Lcn2 with proMMP9 appears to enhance activation of the enzyme by plasma kallikrein and protects the enzyme from degradation [22]. Lcn2 is increased in the synovial fluid of patients with OA where it also acts to protect MMP9 from degradation and enhance MMP9-induced cartilage breakdown [16]. This activity, maintaining MMP9 protein, is likely to explain the observations in the current study where it shows increased expression of MMP9 protein but no change in gene expression in the AF cultures treated with NGF. Similar activity in vivo, if present, in IVD would be expected to enhance tissue degeneration and also potentially influence neoangiogenesis as seen in tumor models [23].

Overexpression of MMPs is clearly associated with both osteoarthritis and IVD degeneration [12]. In the current study, our microarray results indicated that NGF increases 

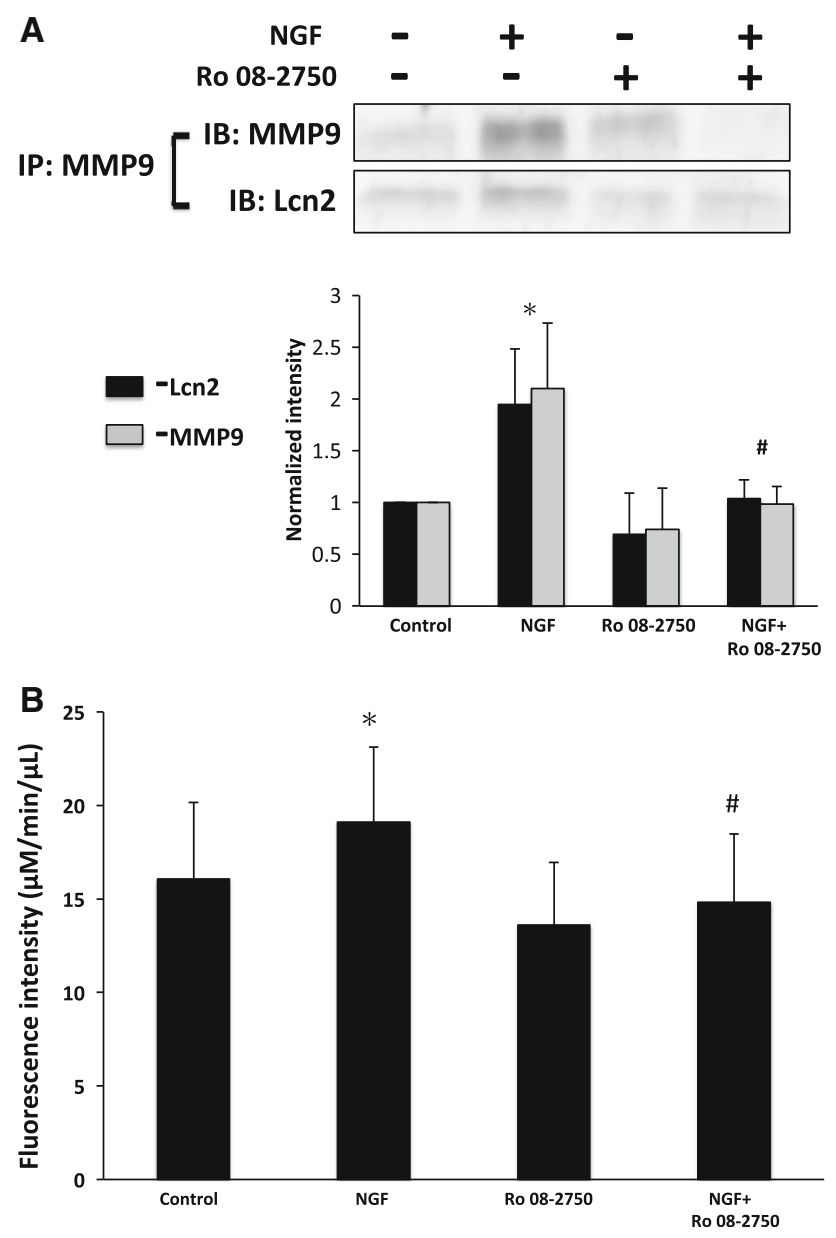

Fig. 5 Presence of Lcn2-MMP9 complex and MMP9 activity in cultured medium. a By immunoprecipitation (IP), Lcn2-MMP9 complex was identified and upregulated by NGF stimulation (NGF vs control, Len2 $1.95 \pm 0.5$-fold; MMP9 $2.1 \pm 0.6$-fold, $* P=0.006$ and 0.01 , respectively) and inhibited by treatment with Ro 08-2750 (NGF vs NGF + Ro 08-2750, ${ }^{\#} P=0.022$ and 0.02 , respectively). Upper panel was a representative gel (IB immunoblotting) and lower panel was the semiquantitative data $(n=6)$. b By FRET assay, MMP9 activity $(\mu \mathrm{M} / \mathrm{min} / \mu \mathrm{L})$ was upregulated by NGF stimulation (Control, $\quad 16.06 \pm 4.09 ; \quad \mathrm{NGF}, \quad 19.12 \pm 4.0 ; \quad$ Ro $08-2750$, $13.6 \pm 3.35$; NGF + Ro 08-2750, $14.83 \pm 3.66$; *NGF vs control, $P=0.039$ ) and inhibited by treatment with Ro 08-2750 (NGF vs $\mathrm{NGF}+$ Ro $\left.08-2750,{ }^{\#} P=0.012\right)(n=6)$

expression of a number of MMPs such as MMP3 and MMP13 consistent with previous investigations that have shown similar activity of NGF in other tissues and cell systems, including smooth muscle cells and pancreatic cancer cells [13, 24]. Increased expression of proteinases in IVD degeneration is presumably predominantly through the activity of catabolic cytokines such as IL-1 $\beta$. Indeed, whilst we were able to demonstrate an effect of NGF on release of GAGs into the media of AF cells in culture, this was less than that seen with IL-1 $\beta$. Although altered levels of GAG in the media are likely to be due to proteolytic activity and release from pericellular matrix, we have not excluded the possibility that increased GAG production may also contribute to the elevated GAG in the media. However, our observations suggest a potentially important role for NGF in the maintenance of Lcn2-MMP9 complex stability and hence activity in IVD degeneration. Thus, as NGF may not only regulate neuronal in-growth but also influence the production of MMPs and neoangiogenesis [14], it may be a prime target for intervention in the course of IVD degeneration to help ameliorate pain and rate of disease progression.

We have obtained initial information on the pathways by which NGF influences AF gene and protein expression. NGF binds to both p75NTR and TrkA NGF receptors (NGFR). p75 is a low affinity NGFR to which all neurotrophins bind, whereas TrkA is a member of the neurotrophic tyrosine kinase receptor (NTKR) family and binds NGF with high affinity. In the presence of TrkA NGFR, p75NTR participates in the formation of high-affinity binding sites resulting in enhanced NGF responsiveness $[25,26]$. Signaling through TrkA NGFR results in activation of a signal cascade including the MAPK-Ras-Erk pathway, phospholipase C and PI3 kinase [27]. The observation that Ro 08-2750, a non-peptide inhibitor of NGF that binds the NGF dimer and inhibits binding to both p75NTR and TrkA increased expression of Lcn2 in the NGF treated AF cells supports a direct role for NGF-NGFR interactions in regulating $\mathrm{AF}$ cell function which may be amenable to therapeutic intervention.

A variety of animal models including bovine, canine, rabbit, rat, and mouse have been used to study IVD degeneration or regeneration in place of human samples [28-30]. In vitro studies that identify potential catabolic mechanisms involved in deserve consideration when formulating a clinical solution to degenerative disc disease. In the current study, we used cells between 3 and 5 passages. Optimal in vitro studies would be with cells at passage 1 or 2 to mitigate against dedifferentiation and senescence. As such these studies will need to be followed up by appropriate in vivo studies. Rat-tail IVD would appear to be a good model system for both in vitro and in vivo studies [31, 32]. We believe that the data in this study support further investigation of the potential of NGF-targeted therapy in the management of IVD disease [6, 33].

\section{Conclusions}

In summary, we have shown for the first time that NGF increases expression of Lcn2 in AF cells and formation of an Lcn2-MMP9 complex promotes a pro-catabolic phenotype. Novel treatments targeting NGF/NGF receptors have the potential to influence a range of adverse biological responses including neurite and vascular infiltration as well 
as tissue degeneration which result in the clinical symptoms and pathology.

Acknowledgments The study was supported by grants from the National Science Council and National Defense Medical Center, TriService General Hospital, Taiwan (NSC100-2320-B-016-006-MY3, MAB102-57, TSGH-C102-069, TSGH-C103-080) and Taichung Veterans General Hospital, Taiwan (TCVGH-1034905B; TCVGHVHCY1038602). We also thank You-Hsiang Chu, Chih-Min Kuo and Ya-Ting $\mathrm{Ku}$ for technical support of our experiments.

Conflict of interest The authors declare no conflict of interest in this article.

Open Access This article is distributed under the terms of the Creative Commons Attribution License which permits any use, distribution, and reproduction in any medium, provided the original author(s) and the source are credited.

\section{References}

1. Schwarzer AC, Wang SC, Bogduk N, McNaught PJ, Laurent R (1995) Prevalence and clinical features of lumbar zygapophysial joint pain: a study in an Australian population with chronic low back pain. Ann Rheum Dis 54:100-106

2. Schwarzer AC, Aprill CN, Derby R, Fortin J, Kine G, Bogduk N (1995) The prevalence and clinical features of internal disc disruption in patients with chronic low back pain. Spine 20:1878-1883

3. Miyagi M, Ishikawa T, Kamoda H, Suzuki M, Murakami K, Shibayama M, Orita S, Eguchi Y, Arai G, Sakuma Y, Kubota G, Oikawa Y, Ozawa T, Aoki Y, Toyone T, Takahashi K, Inoue G, Kawakami M, Ohtori S (2012) ISSLS prize winner: disc dynamic compression in rats produces long-lasting increases in inflammatory mediators in discs and induces long-lasting nerve injury and regeneration of the afferent fibers innervating discs: a pathomechanism for chronic discogenic low back pain. Spine 37:1810-1818. doi:10.1097/BRS.0b013e31824ffac6

4. Kallewaard JW, Terheggen MA, Groen GJ, Sluijter ME, Derby R, Kapural L, Mekhail N, van Kleef M (2010) 15. Discogenic low back pain. Pain Pract 10:560-579. doi:10.1111/j.1533-2500.2010. 00408.x

5. Freemont AJ, Peacock TE, Goupille P, Hoyland JA, O'Brien J, Jayson MI (1997) Nerve ingrowth into diseased intervertebral disc in chronic back pain. Lancet 350:178-181

6. Davis TT, Delamarter RB, Sra P, Goldstein TB (2004) The IDET procedure for chronic discogenic low back pain. Spine 29:752-756

7. Tsou HK, Chao SC, Wang CJ, Chen HT, Shen CC, Lee HT, Tsuei YS (2010) Percutaneous pulsed radiofrequency applied to the L-2 dorsal root ganglion for treatment of chronic low-back pain: 3-year experience. J Neurosurg Spine 12:190-196. doi:10.3171/ 2009.9.SPINE08946

8. Rezaeian $\mathrm{AH}$, Isokane $\mathrm{T}$, Nishibori $\mathrm{M}$, Chiba $\mathrm{M}$, Hiraiwa $\mathrm{N}$, Yoshizawa M, Yasue H (2009) alphaCGRP and betaCGRP transcript amount in mouse tissues of various developmental stages and their tissue expression sites. Brain Dev 31:682-693. doi:10.1016/j.braindev.2008.10.011

9. Zhou XF, Deng YS, Chie E, Xue Q, Zhong JH, McLachlan EM, Rush RA, Xian CJ (1999) Satellite-cell-derived nerve growth factor and neurotrophin-3 are involved in noradrenergic sprouting in the dorsal root ganglia following peripheral nerve injury in the rat. Eur J Neurosci 11:1711-1722
10. Barthel C, Yeremenko N, Jacobs R, Schmidt RE, Bernateck M, Zeidler H, Tak PP, Baeten D, Rihl M (2009) Nerve growth factor and receptor expression in rheumatoid arthritis and spondyloarthritis. Arthritis Res Ther 11:R82. doi:10.1186/ar2716

11. Imai S, Matsusue Y (2002) Neuronal regulation of bone metabolism and anabolism: calcitonin gene-related peptide-, substance $\mathrm{P}-$, and tyrosine hydroxylase-containing nerves and the bone. Microsc Res Tech 58:61-69. doi:10.1002/jemt.10119

12. Le Maitre CL, Pockert A, Buttle DJ, Freemont AJ, Hoyland JA (2007) Matrix synthesis and degradation in human intervertebral disc degeneration. Biochem Soc Trans 35:652-655. doi:10.1042/ BST0350652

13. Khan KM, Falcone DJ, Kraemer R (2002) Nerve growth factor activation of Erk-1 and Erk-2 induces matrix metalloproteinase-9 expression in vascular smooth muscle cells. J Biol Chem 277:2353-2359. doi:10.1074/jbc.M108989200

14. Nico B, Mangieri D, Benagiano V, Crivellato E, Ribatti D (2008) Nerve growth factor as an angiogenic factor. Microvasc Res 75:135-141. doi:10.1016/j.mvr.2007.07.004

15. Kao TH, Peng YJ, Tsou HK, Salter DM, Lee HS (2014) Nerve growth factor promotes expression of novel genes in intervertebral disc cells that regulate tissue degradation. J Neurosurg Spine 21:653-661. doi:10.3171/2014.6.SPINE13756

16. Gupta K, Shukla M, Cowland JB, Malemud CJ, Haqqi TM (2007) Neutrophil gelatinase-associated lipocalin is expressed in osteoarthritis and forms a complex with matrix metalloproteinase 9. Arthritis Rheum 56:3326-3335. doi:10.1002/art.22879

17. Sato M, Kikuchi T, Asazuma T, Yamada H, Maeda H, Fujikawa $\mathrm{K}$ (2001) Glycosaminoglycan accumulation in primary culture of rabbit intervertebral disc cells. Spine 26:2653-2660

18. Richardson SM, Purmessur D, Baird P, Probyn B, Freemont AJ, Hoyland JA (2012) Degenerate human nucleus pulposus cells promote neurite outgrowth in neural cells. PLoS One 7:e47735. doi:10.1371/journal.pone.0047735

19. Triebel S, Blaser J, Reinke H, Tschesche H (1992) A $25 \mathrm{kDa}$ alpha 2-microglobulin-related protein is a component of the $125 \mathrm{kDa}$ form of human gelatinase. FEBS Lett 314:386-388

20. Owen HC, Roberts SJ, Ahmed SF, Farquharson C (2008) Dexamethasone-induced expression of the glucocorticoid response gene lipocalin 2 in chondrocytes. Am J Physiol Endocrinol Metab 294:E1023-E1034. doi:10.1152/ajpendo.00586. 2007

21. Leung L, Radulovich N, Zhu CQ, Organ S, Bandarchi B, Pintilie M, To C, Panchal D, Tsao MS (2012) Lipocalin2 promotes invasion, tumorigenicity and gemcitabine resistance in pancreatic ductal adenocarcinoma. PLoS One 7:e46677. doi:10.1371/jour nal.pone. 0046677

22. Tschesche H, Zolzer V, Triebel S, Bartsch S (2001) The human neutrophil lipocalin supports the allosteric activation of matrix metalloproteinases. Eur J Biochem/FEBS 268:1918-1928

23. Fernandez CA, Yan L, Louis G, Yang J, Kutok JL, Moses MA (2005) The matrix metalloproteinase-9/neutrophil gelatinaseassociated lipocalin complex plays a role in breast tumor growth and is present in the urine of breast cancer patients. Clin Cancer Res 11:5390-5395. doi:10.1158/1078-0432.CCR-04-2391

24. Okada Y, Eibl G, Guha S, Duffy JP, Reber HA, Hines OJ (2004) Nerve growth factor stimulates MMP-2 expression and activity and increases invasion by human pancreatic cancer cells. Clin Exp Metastasis 21:285-292

25. Hempstead BL (2002) The many faces of p75NTR. Curr Opin Neurobiol 12:260-267

26. Micera A, Lambiase A, Stampachiacchiere B, Bonini S, Bonini S, Levi-Schaffer $F$ (2007) Nerve growth factor and tissue repair remodeling: trkA(NGFR) and p75(NTR), two receptors one fate. Cytokine Growth Factor Rev 18:245-256. doi:10.1016/j.cytogfr. 2007.04.004 
27. Chacon PJ, Arevalo MA, Tebar AR (2010) NGF-activated protein tyrosine phosphatase $1 \mathrm{~B}$ mediates the phosphorylation and degradation of I-kappa-Balpha coupled to NF-kappa-B activation, thereby controlling dendrite morphology. Mol Cell Neurosci 43:384-393. doi:10.1016/j.mcn.2010.01.005

28. Stevens JW, Kurriger GL, Carter AS, Maynard JA (2000) CD44 expression in the developing and growing rat intervertebral disc. Dev Dyn 219:381-390. doi:10.1002/1097-0177(2000)9999: 9999<:AID-DVDY1060>3.0.CO;2-P

29. Fujita N, Miyamoto T, Imai J, Hosogane N, Suzuki T, Yagi M, Morita K, Ninomiya K, Miyamoto K, Takaishi H, Matsumoto M, Morioka H, Yabe H, Chiba K, Watanabe S, Toyama Y, Suda T (2005) CD24 is expressed specifically in the nucleus pulposus of intervertebral discs. Biochem Biophys Res Commun 338:1890-1896. doi:10.1016/j.bbrc.2005.10.166

30. Lee CR, Sakai D, Nakai T, Toyama K, Mochida J, Alini M, Grad S (2007) A phenotypic comparison of intervertebral disc and articular cartilage cells in the rat. Eur Spine J 16:2174-2185. doi:10.1007/s00586-007-0475-y
31. Orita S, Ohtori S, Taniguchi A, Yamashita M, Yamauchi K, Inoue G, Suzuki M, Eguchi Y, Ochiai N, Kishida S, Takaso M, Aoki Y, Takahashi K, Kawakami M (2010) Direct evidence for sensory innervation of the dorsal portion of the Co5/6 coccygeal intervertebral disc in rats. Spine 35:1346-1352. doi:10.1097/ BRS.0b013e3181c099b0

32. Yurube T, Takada T, Suzuki T, Kakutani K, Maeno K, Doita M, Kurosaka M, Nishida K (2012) Rat tail static compression model mimics extracellular matrix metabolic imbalances of matrix metalloproteinases, aggrecanases, and tissue inhibitors of metalloproteinases in intervertebral disc degeneration. Arthritis Res Ther 14:R51. doi:10.1186/ar3764

33. Zhang Y, Chee A, Thonar EJ, An HS (2011) Intervertebral disk repair by protein, gene, or cell injection: a framework for rehabilitation-focused biologics in the spine. PM R 3:S88-S94. doi:10.1016/j.pmrj.2011.04.020 